\title{
POSTGRADUATE WRITING GROUPS AS SPACES OF AGENCY DEVELOPMENT
}

D. O. Oluwole*

e-mail: d.oluwole@ru.ac.za

O. Achadu*

e-mail: ojodomo2000@yahoo.com

F. Asfour*

e-mail: fouadas@gmail.com

G. Chakona*

e-mail: matarutseg@yahoo.com
P. Mason*

e-mail: pm6308@gmail.com

P. Mataruse*

e-mail: mayibuyesimba@gmail.com

\section{S. McKenna*}

e-mail: s.mckenna@ru.ac.za

${ }^{*}$ Centre for Postgraduate Studies

Rhodes University

Grahamstown, South Africa

\section{ABSTRACT}

Academic writing is a peculiar phenomenon - it varies greatly from discipline to discipline and its requirements are rarely made overt. Taking on the writing practices of the academy has implications for identity and it is thus unsurprising that it is seen to be a risky endeavour. This article analyses the experiences of postgraduate scholars who have participated in writing groups that meet weekly to read each other's work and provide supportive critique. Thirty-two people provided detailed, anonymous evaluations of their writing groups and these were studied using a discourse analysis. Three main findings are discussed here. Firstly, writing circles allowed for academic writing development to be engaged with as a social practice, where the disciplinary norms could be made more explicit through peer deliberation, and where they could also be challenged. Secondly, the lack of hierarchical power in the writing groups was key to making safe spaces for agency development, and also for providing positive peer pressure whereby participants were spurred on to work on their writing. Thirdly, the fact that the groups were interdisciplinary, within cognate disciplinary families, provided an interesting challenge in that the students had to consider what these non-specialist readers would or would not understand. This process assisted students in clarifying their writing. Participants' evaluation of the writing groups revealed an overall sense that these contributed to postgraduate student wellbeing and were places of significant agential development.

Keywords: writing groups, wellbeing, academic identities, peer-support, academic agency

\section{INTRODUCTION}

"When Andile ${ }^{1}$ read in one of her MSc examiner's reports that 'She writes with an advanced academic style. Reading the core chapters really felt like reading a series of published journal articles', her first response was to contact her writing group on WhatsApp. 'Stick around in the 
writing circles and you will most likely get reviews like these ... deeply appreciate all your help guys.', she texted."

Writing groups, also known as writing circles, are peer-led spaces where students meet to read and comment on each other's work. Groups typically meet weekly for an hour or so and often circulate a piece of writing prior to the meeting. Everything from the regularity of meeting to the agenda for the day is negotiated amongst participants. Given that the "academic expert" is absent in this space, it provides an interesting context in which to develop agency. This article reflects on the use of postgraduate writing groups at Rhodes University and analyses anonymous questionnaire data to make sense of how these groups contribute to students' sense of wellbeing and the nurturing of their academic identities.

Wellbeing is an increasingly prominent concern in research on student experience (Harward 2016), and frequent mention is made of the extent to which feelings of alienation and isolation in the academy can work against wellbeing. In this study, we understand wellbeing to emerge from a sense of being valued and from a sense of tackling challenges in order to work towards a purpose.

\section{LITERACIES APPROACH TO WRITING GROUPS}

The "writing up" part of the postgraduate thesis has often been sidelined in a focus on field, laboratory or studio work. The peer-facilitated initiative reported on embedded writing with research and made space for acknowledging the writing process as knowledge-creating rather than as knowledge-recording (Aitchison and Lee 2006). There is no research without written, recognizable products that transcend the research site to share and translate insights into knowledge that makes a difference (Thesen 2013, 104). However, this process is neither neutral nor generic as it is influenced by the norms, values and expectations of institutions, supervisors, reviewers, examiners, editors, and, importantly, the discipline itself (Maton 2014).

While the dominant outcome of the Master's and Doctoral degree remains an individually written thesis, there is now a wealth of literature indicating that the acquisition of appropriate literacy practices is not an individual act (see, for example, Lea and Street 2006; Lillis and Scott 2007). An understanding that acquiring the writing practices of the discipline can benefit from social engagement is tied to an understanding of academic writing as a social practice. In this conception, the norms and values of our universities and disciplines are seen to infuse the ways in which we represent knowledge in writing and thus becoming adept at expressing research in text is not a simple matter of learning the terminology, grammar and punctuation.

Writing groups function as supportive spaces in which peers write collectively and learn from one another (Chihota 2007; Li and Vandermensbrugghe 2011). They work by building up 
a concerted image of what postgraduate education is all about (Larcombe, McCosker and O'Loughlin 2007; Aitchison 2003). Writing groups thus function within an academic literacies' approach whereby writing is understood to be a social practice emerging in part from the cultural norms and values of the discipline and acquired through opportunities to engage in such practices in scaffolded ways where feedback is supportive and collegial.

Once academic writing is understood to be a social, political and cultural practice, rather than a generic, neutral skill, it becomes evident that having communal spaces for the acquisition and critique of such practices might be useful. The data reported on here suggests that through the writing groups, writing became a normal everyday activity - a social practice for postgraduate students at Rhodes University seeking peer-support for the arduous process of writing a thesis.

\section{CASE STUDY}

After a pilot in 2015, Rhodes University Writing Groups were started in 2017 by the Centre for Postgraduate Studies (see Wilmot and McKenna 2018 for further discussion of the process). Posters and emails advertising the groups were sent out with a hyperlink through which to sign up. Groups were designated HSS \& SS or NS, that is Humanities and Social Sciences or Natural Sciences, though there was no further division by department or discipline. Students were assigned to a writing group based on their schedule availability. Each of the groups was facilitated by a postdoctoral fellow or a doctoral student at Rhodes University from across the faculties. There were thirteen writing groups in 2017 , with participant numbers varying week by week from four to eight postgraduate scholars per group.

The facilitators were provided with some key readings on academic literacy and in particular they were provided with the document that had been written up during the 2015 pilot about the theory of academic literacy development underpinning the project (Wilmot 2015) and a source book including suggested activities for various writing initiatives (Wilmot and LotzSisitka 2016). The facilitators met regularly to discuss their experiences of the groups and to share ideas of activities, but the only "rule" was that they were not positioned as writing experts. The writing groups had, at their heart, an understanding that the nature and practices of the writing groups would be collaboratively determined by the groups as a whole. The facilitators' chief role was thus to co-ordinate practical issues of times and venues, and to communicate with the group (usually via Whatsapp). ${ }^{2}$

The Writing Groups met once a week to share and evaluate each other's academic work and participate in some writing exercises and general discussions on writing. The modus operandi of the groups is simple, and the "rules" co-constructed. During each meeting, topics 
of interest as decided by the members are chosen for discussion. Many groups were characterized by the review and evaluation of the work-in-progress by participating members. Usually written work is circulated in advance, and some level of analysis, critiquing and inputs are done at the meetings. Sometimes the sessions comprised participants reading sections of their draft work aloud. Often, organized sessions were planned where citation software techniques, referencing styles or other skills were shared. The meeting format of the writing groups thus varied greatly with sessions lasting about one or two hours.

\section{METHODOLOGY}

In order to evaluate the ways in which the writing groups have contributed to student well-being and the development of agency, data was sought from participants towards the end of 2017. The questionnaire was developed by the six facilitators and the director of the Centre for Postgraduate Studies and was distributed via Google Forms. All participants of the writing groups, including those who had only attended a few sessions, were sent the link and asked to voluntarily and anonymously complete the questionnaire. Responses to the questionnaire were collected from thirty-two participants and were analysed using a discourse analysis. Simply put, discourses are understood to be "systematically organised sets of statements which give expression to meanings and values" (Kress 1989, 7).

We brought to this process an ontological position that discourses have power to enable and constrain events and experiences from emerging (Fairclough, Jessop and Sayer 2002). Discourses are thus understood to be more than the relative and shifting reflections of the writing group participants on their experiences, instead they are understood to be mechanisms that can either constrain or enable the ways in which we think and act (Fairclough 2005). Discourses are not the only mechanisms at play in the ways in which events (such as writing groups) emerge or the ways in which events are experienced (captured as questionnaire reflections on such writing groups). Multiple mechanisms in the structural and cultural domain would all exert power over how the writing groups take place and are experienced, but we were particularly focused on the discursive mechanisms in order to make better sense of the ways in which the participants' experiences related to the emergence of their agency. Agency refers to the ability to take action (Porpora 2013), or the ability of agents to work with the given culture and structure to pursue their own personal projects (Archer 1995, 2000).

We took this understanding of discourses to the responses garnered through the online questionnaire to identify how the participants were discursively constructing the role of the writing groups and how they understood the academic writing process. The remainder of the article presents three key discourses that emerged from the data and which suggest that writing 
groups contributed to postgraduate student wellbeing and were places of significant agential development.

\section{WRITING AS SOCIAL PRACTICE}

A central discourse that emerged in the data related to the social nature of the groups and writing. Firstly, the data suggests that participants valued being together to support and develop their writing, especially as writing was previously considered by most of them to be an individual act.

It made me aware of my form and style; practice writing, reading, listening and giving feedback; learning from how others approach their work; sharing practice; unravelling theories; openness; support; collegiality, wisdom, experience, viewpoints and critical thinking/sensing.

And secondly, alongside the social aspect of developing writing collectively, was the emergence of a discourse of the act of academic writing as being a social practice - where "social" is the acknowledgement that the norms of academic writing are political, historical, cultural etc. and "practice" is the acknowledgement that academic writing expertise is not an inherent trait but rather one can develop over time.

Whilst I find academic writing exceedingly difficult, thanks to the writing group sessions I attended. I came to enjoy it for a number of reasons. I became far more aware of my own writing style. Gradually I became less embarrassed about my style of writing. I also became more conscious of how I put words on paper. Actually, these writing groups were one of the reasons I have continued to pursue my $\mathrm{PhD}$.

It was evident from the data that the groups do not just provide spaces to acknowledge that writing is social, but they also respond to and address the sociality of writing (Aitchison and Lee 2006). Some of the activities undertaken in the groups were deliberations about stages in the writing process, critiquing written work, developing the skills for giving and receiving feedback, and practicing conference and other presentations. Most of the activities were explicitly negotiated, self-directed, evolving responses to the group agendas and needs (Aitchison and Lee 2006) and thus closely tied to the emergence of agency.

"We also dealt with and prepared ethical clearance documents, consent forms, and our research instruments such as questionnaires. Lastly, we also practiced and discussed on the writing of abstracts."

"I had never heard of the Pomodoro technique, ${ }^{3}$ and it most certainly encouraged me to start writing - to start with just reflective notes, to get into the habit of writing. I also use this technique at home - as being full time employed, it is difficult to be a part-time student and find time to read 
and write, but this has helped me incredibly."

Importantly, the writing groups worked outside of the deficit model (Smit 2012) so prevalent in the academy, whereby students are understood to be removed from their histories, norms and values (Boughey and McKenna 2016). The integration of the writing group into these postgraduate students' learning schedule ensured that the messy writing development was understood to be a normal part of the postgraduate experience. The process helped to disabuse students of the notion that writing difficulties can be overcome simply by the application of a few techniques. Instead, writing was found to be "a continuous growing process". In some instances, students in the writing groups pushed for a daily writing routine and stuck to it until they managed to finish their postgraduate degrees. The writing group was therefore seen as a space where struggles in putting writing ideas together are overcome with practice and collaboration.

"A space to dialogue about something that is not often talked about and is usually taken for granted in my experience of university in South Africa. It's an important part of the praxis of research. It also offered a way to get feedback."

"They offered me a space to experience the work of other people and a chance to interact with this work in very meaningful ways."

"It gave me the opportunity to place myself in the position of the audience when writing, to be coherent in ideas."

At times, discussions would go beyond the piece of writing to a concern with other issues that may appear removed from the writing process but were in fact closely related to it. Writing groups became important forums for deliberating other challenges and even successes that would have otherwise gone without recognition - such as finishing a chapter, sourcing a muchneeded book or overcoming the experience of writer's block.

\footnotetext{
"We would also chat. Vent about writing related issues. Get to know each other a little bit better. Drift off into a conversation about politics, life, etc. It became a form of group therapy for writing and academic related pressures."

"The first time we discussed the writing of a peer. It was very interesting especially as we all tried to write out the main argument of his work. The second session I brought some writing for discussion. I am afraid I did a bad job at communicating with this piece. I was not engaging critically enough with the work and I think I was making claims without evidence. I was grateful to have this space to understand how to bring different writers into conversation around a concept and be wary of 'settler moves to innocence' in writing about transformative learning."
}

Data revealed that writing groups generated a changing relationship to texts, as each participant 
gained confidence in recognizing their own and other's literacy practices and came to establish their agency in making decisions about these. There was evidence that the writing groups supported a shift from approaching readings as sacred texts to be summarized, and to read them instead as contributions to the student's own research concerns which they had the agential power to engage with, draw upon, or challenge. In other words, data reveals that the writing groups served to promote an attitude of scholarly independence, and thereby foster higher levels of agency.

"Listening to other students reading their work gave me the chance to check my own understanding and knowledge of academic writing. By offering suggestions and joining in the discussion, I feel as though I am finding my own 'academic voice'."

In the writing groups participants often asked the difficult "So what?" questions, pushing each other towards a direct focus on development of "voice" in the context of their discipline (Tang 2012). In this way, the data suggests that academic writing ceased to be seen as natural or neutral and the community of the writing group results in excavating the underlying assumptions of a text or discipline for scrutiny. Wilmot and McKenna (2018) indicate that these processes enable writing groups to become transformative spaces where dominant literacy practices can be overtly challenged. This was also evident in the data collected in this study:

"Like all other types of writing, academic writing is framed by colonialism as [if it is] an objective form of writing ... As a form, and as writing goes, it improves through writing and support, which together orientates the writer towards the form. ... As a de-colonial scholar, the challenge is about 'de-linking' from the colonial form and style, ... being conscious about what ideas, values and principles I am promoting through my references and maintaining the standard of academic writing .... So, the writing circles have been imperative for me because it allows me to be both writer and reader of academic writing, which in turn helps me to improve and support simultaneously through the practice of writing critically, reading critically and providing feedback that enhances these practices."

While some Writing Group facilitators and participants brought with them sophisticated academic literacy practices - some had, for example, already published in their fields - this was not evenly spread across the groups, and it was central to the anti-hierarchical stance that nobody was deemed to be more important. The groups were about collective engagement, and this was "both a matter of intellectual honesty as well as empowerment" (Choudry 2015, 13).

"Well, eventually you learn that nobody is ever really a writing expert. Facilitator had very good core knowledge of academic writing and was able to explain some concepts but every member was able to contribute some knowledge to the group in many ways." 
"The result was that everybody was engaged in a process of learning and teaching in a manner that did not centre around the facilitator."

"I love that we are a team with the same goals, no-one is professional, all of us are learning and so we have the same mindset to finish our work and to finish right."

In a country like South Africa where certain experiences have been silenced, a writing group's situated pedagogy may be an important move "from silence to words," ( $\mathrm{Lu} \mathrm{1998,} \mathrm{71).}$ Marginalized voices or voices in conflict with the established approaches are brought into dialogue with dominant discourses in the space of the writing group (Wilmot and McKenna 2018). Not only did students that might otherwise have dropped out or missed their writing deadlines realize their capacity to move forward, but there was a general depth and personal engagement with texts that all postgraduate students who participated found both enabling and liberating.

\section{SAFE SPACES WITH PEER CRITIQUE}

"They offered me a safe space to try out my writing before I submitted it to my supervisor which gave me the confidence and the motivation to 'give it a whirl'."

"The benefits are numerous especially for a self-conscious writer."

"I could hear my own mistakes when I read aloud to the audience which was an ideal opportunity for me to self-correct and critique my own writing without feeling vulnerable."

The Writing Groups did not provide "tips", they provided spaces where feelings of incompetence or frustration could be engaged with safely. The data suggests that it was not only the "safety" of the groups that was significant, it was also that they fostered an interpersonal dynamic of shared responsibility and constructive engagement.

"Only when I joined the writing circle did I start moving at a much faster pace, and progress in terms of writing and work was very evident. The groups were small so I felt that I received personal attention."

"They offered me a space to experience the work of other people and a chance to interact with this work in very meaningful ways. It also pressed me to become clearer and more open in the way that I write ...."

Participants' responses to the questionnaire revealed that the establishment of a space in which students feel safe or at ease depends in part upon the success of the opening session. Because it is crucial that Writing Groups meet the distinctive needs of each of the students who choose to attend them, it is best for this opening session to be devoted to each student providing as clear 
a sense as possible of the content of their research projects, as well as providing a sense of what they hope to gain from the Writing Groups. This sharing of input served to establish a distinct and workable awareness of personal and interpersonal co-ordinates, which in its turn ensured optimal use of the time available for the writing groups meetings to follow.

The testimony of a number of students revealed a general feeling of safety or ease, as well as suggesting actual or tangible results that arise therefrom:

"I found the writing circle to be beneficial as a space for support during this lonely phase of thesis writing."

"[Participation in Writing Groups meant] finding camaraderie in the writing process, as writing is in itself lonely."

Some students expressed the absence of the human dimension as rooted in their relationships with their supervisors. Although it is not necessarily of use here to apportion blame for this disparity between the student's needs and the supervisor's availability, it is important to acknowledge it as a problem that asks to be addressed. Writing groups constitute just such an acknowledgement of and active response to this problem. Writing groups provide postgraduate students with the opportunity to structure their time in ways they would not necessarily be able to do alone:

"The sessions were well structured and held everyone accountable. Each session everyone was expected to tell the group what their goal was for the day, week or month. We'd each then track each other's progress."

There was thus a sense for some of the participants that they were accountable to the group and the effects of "positive peer pressure" was evident in the data. For example, having mentioned the "commitment and reciprocity" in the group she attended, one participant indicated that:

“... when one of the group completed their essay or proposal which was supported by the group, it became a celebration of the entire group's contribution. This, in turn, proved how well we were doing as a group because the individual took the feedback seriously and achieved their goal with and because of the support."

Understandably, students who attended the writing groups on a weekly basis stood to gain the most from these meetings. Such students pointed to the role writing groups played in helping them to meet deadlines, notably the deadlines of submitting their proposals to their supervisors and the Higher Degrees Committee. In this regard, one participant noted that the intense revision and editing that took place in the writing groups made it possible to "submit to [her] supervisor on time for his feedback". 


\section{INTERDISCIPLINARITY}

While the groups were divided into Humanities and Social Sciences on the one hand and Natural Sciences on the other, there were no department, programme or topic groupings and so Fine Art, Education and Philosophy students could find themselves within one group, for example, while Geology, Physics and Ichthyology students might be together in another. It was clear from the data that being in such interdisciplinary groups was seen to be an advantage.

"It gave me the chance to learn what other people were working on, and ... it gave me the opportunity to create links for collaborative research. This was the case as we were able to identify some aspects of similarities in the work that people were doing in their research."

"I particularly enjoyed the interdisciplinary nature of the writing circles. I enjoyed learning of other people's passions and sharing my passion with the group. We were often fascinated by the like-minded thinking and great ideas and engagement. Sharing work with [students from other disciplines] really helped me to consciously simplify my writing which aided the overall flow ... of my work."

"I sometimes felt a bit odd as I was the only one not in Fine Art. I felt a bit undeveloped in terms of ways of thinking about writing. I did think about seeking a writing circle more specific to Education but I so enjoyed the engagement of this writing circle that I continued as much as I could with it."

"I think that the diversity allows for more clarity in the work we are doing. It presses us as participants to be clear and concise in what we are saying and in how we are writing."

"It allows for a cross-disciplinary approach as well, which requires understanding and fosters a community outside of ones' own department or discipline and I think that this is very important. This is specifically important as we can at times become so isolated and subsequently create our own little enclaves as a result of the work we are doing. This space presses us to reach out to other people and prepares us for the task of sharing our research in meaningful and interesting ways."

There was however at least one participant who indicated that discipline specific writing groups would allow for more detailed engagement with the literacy practices of the specific field:

"Maybe we try to group people by department and not faculty. Sometimes we find it hard following from other fields of study and get lost along the way."

\section{CONCLUSION}

The data analysed here suggests that the discourses constructing the writing groups enabled participants to take on an understanding of academic writing as a social practice. This enabled the development of both the participants' writing practices and their agency as novice academic writers. It would seem that writing groups afford what Aitchison and Lee (2006) argue to be three important elements: mutuality, expertise and writer identity. Mutuality is key in building trust and the data suggests this was achieved in that the writing groups were non hierarchical or 
"safe spaces", and that each group's activities were explicitly negotiated and designed to attend to articulated needs. Data revealed that Writing Groups aided development of scholarly expertise via the practice of giving and receiving feedback. Additionally, respondents to the questionnaire frequently referred to the development of their academic writing identities through various group interactions and activities.

While the structure and discursive culture of the writing groups thus seems to have contributed to the development of agency amongst participants, it needs to be noted that such initiatives do not work separately from broader structural and cultural mechanisms (Archer 2005). The institution in which these writing groups take place had adopted the stance that writing was not a technical process but was gradual and messy and an integral and normal part of knowledge development. This can be seen in various initiatives beyond the writing groups, such as writing intensive courses offered at undergraduate level (Wilmot 2015; Wilmot and Lotz-Sisitka 2016; Wilmot and McKenna 2018), and in various policies (such as the "Plagiarism Policy", which explicitly references the need for students to be inducted into the writing norms of the discipline).

Thus, while peer led spaces for writing development need to be well managed and theoretically grounded, the data in this study suggests that they have much to offer in the negotiation of academic agency and the nurturing of writing practices.

\section{NOTES}

1. All data is used with permission. Pseudonyms are used throughout.

2. It should be noted that though the facilitators brought different levels of academic writing expertise, it was very quickly evident that all had a rich interest in theorising the workings of the writing groups, and thus this article has collectively emerged through collaborative data collection, analysis and writing by the six facilitators and the director of postgraduate studies.

3. The Pomodoro technique is a simple timed writing technique where distractions are avoided (for example wifi and cellphones are turned off) and the group writes for 25 minutes at a time. https://francescocirillo.com/pages/pomodoro-technique

\section{REFERENCES}

Aitchison, C. 2003. Thesis writing circles. Hong Kong Journal of Applied Linguistics 8(2): 97-115.

Aitchison, C. and A. Lee. 2006. Research writing: Problems and pedagogies. Teaching in Higher Education 11(3): 265-278.

Archer, M. 1995. Realist social theory: The morphogenetic approach. New York. Cambridge University Press.

Archer, M. 2000. Being human: The problem of agency. New York. Cambridge University Press.

Boughey, C. and S. McKenna. 2016. Academic Literacy and the decontextualized learner. Critical Studies in Teaching and Learning 4(2): 1-9.

Chihota, M. C. 2007. "The games people play": Taking on postgraduate identities in the context of writer 
circles. Journal of Applied Linguistics 4(1): 131-136.

Choudry, A. A. 2015. Learning activism: The intellectual life of contemporary social movements. Ontario: University of Toronto Press.

Fairclough, N. 2005. Peripheral vision: Discourse analysis in organization studies: The case for critical realism. Organization Studies 26(6): 915-939.

Fairclough, N., B. Jessop and A. Sayer. 2002. Critical realism and semiosis. Journal of Critical Realism 5(1): $2-10$.

Harward, D. W. 2016. (Ed.). Well-being and higher education: A strategy for change and the realization of education's greater purposes. Washington, DC: Bridging Theory to Practice.

Kress, G. 1989. Linguistic processes in sociocultural practice. Oxford: Oxford University Press.

Larcombe, W., A. McCosker and K. O'Loughlin. 2007. Supporting education PhD and DEd students to become confident academic writers: An evaluation of thesis writers' circles. Journal of University Teaching and Learning Practice 4: 54-63. http://ro.uow.edu.au/jutlp/vol4/iss1/6

Lea, M. and B. Street. 2006. The "academic literacies" model: Theory and applications. Theory into Practice 45(4): 368-377. doi:10.1207/s15430421tip4504_11.

Li, L. and J. Vandermensbrugghe. 2011. Supporting the thesis writing process of international research students through an ongoing writing group. Innovations in Education and Teaching International 48: 195-205. doi:10.1080/14703297.2011.564014.

Lillis, T. and M. Scott. 2007. Defining academic literacies research: Issues of epistemology, ideology and strategy. Journal of Applied Linguistics 4(1): 5-32. doi:10.1558/japl.v4i1.5.

Lu, M. 1998. From silence to words: Writing as struggle. In Negotiating academic literacies: Teaching and learning across languages and cultures, ed. Vivian Zamel.

Maton, K. 2014. Knowledge and knowers: Towards a realist sociology of education. London: Routledge.

Porpora, D. Y. 2013. Morphogenesis and social change. In Social morphogenesis, ed. M. S. Archer. Dordrecht. Springer.

Smit, R. 2012. Towards a clearer understanding of student disadvantage in higher education: Problematising deficit thinking. Higher Education Research \& Development 31(3): 369-380

Tang, R. 2012. The issues and challenges facing academic writers from ESL/EFL. In Contexts: An Overview, ed. Ramona Tang. London: Continuum International Publishing Group.

Thesen, I. 2013. Risk in postgraduate writing: Voice, discourse, and edgework. CriSTaL 1(1): 103-122.

Wilmot, K. and S. McKenna. 2018. Writing groups as transformative spaces. Higher Education Research and Development.

Wilmot, K. 2015. Supporting academic writing practices in postgraduate studies: A theoretical overview. www.ru.ac.za/postgraduategateway

Wilmot, K. and H. Lotz-Sisitka. 2016. Supporting academic writing practices in postgraduate studies. www.ru.ac.za/postgraduategateway 